\title{
Retraction Note: Decreased microRNA-452 expression and its prognostic significance in human osteosarcoma
}

Ren-Zeng Li $\mathrm{i}^{1,2}$ and Li-Min Wang ${ }^{1 *}$

\section{Retraction note: World J Surg Oncol}

https://doi.org/10.1186/s12957-016-0900-y

The Editor-in-Chief is retracting this article [1] due to overlap with previously published articles $[2,3]$. Fig. 3D "miR-452 mimics" is very similar to Fig. 3D "si-BANCR" in article [2]. Fig. 3D "miRNC" is very similar to Fig. 3E "si-NC" in article [2] and to Fig. 3E "miR-224 mimics" in article [3].

None of the authors responded to any correspondence from the Editor-in-Chief or publisher regarding this retraction.

\section{Author details}

'Department of Orthopedics, The First Affiliated Hospital of Zhengzhou University, Zhengzhou 450000, Henan Province, People's Republic of China. ${ }^{2}$ Department of Orthopedics, People No.3 Hospital of Anyang, Anyang 455000, Henan Province, People's Republic of China.

Published online: 14 June 2019

\section{References}

1. Li R-Z, Wang L-M. Decreased microRNA-452 expression and its prognostic significance in human osteosarcoma. World J Surg Oncol. 2016;14:150. https://wjso.biomedcentral.com/articles/10.1186/s12957-016-0900-y.

2. Zhou T, Gao Y. Increased expression of LnCRNA BANCR and its prognostic significance in human hepatocellular carcinoma. World J Surg Oncol. 2016; 14:8. https://wiso.biomedcentral.com/articles/10.1186/s12957-015-0757-5.

3. Zhu D, Chen H, Yang X, Chen W, Wang L, Xu J, Yu L. Decreased microRNA224 and its clinical significance in non-small cell lung cancer patients. Diagn Pathol. 2014;9:198. https://diagnosticpathology.biomedcentral.com/articles/ 10.1186/s13000-014-0198-4.

\footnotetext{
*Correspondence: manuwanglm@163.com

'Department of Orthopedics, The First Affiliated Hospital of Zhengzhou University, Zhengzhou 450000, Henan Province, People's Republic of China Full list of author information is available at the end of the article
} 